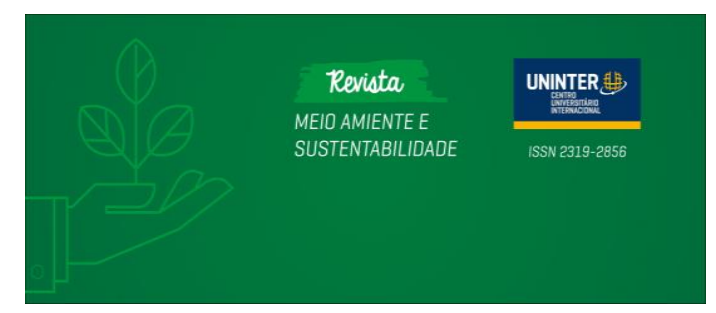

\title{
Reflexionando sobre o licenciamento ambiental de barragens de rejeitos Minerais em Minas Gerais (Brasil)
}

\author{
Marília Mascarenhas Lima \\ Mestre em Genética, Biodiversidade e \\ Conservação pela Universidade Estadual do \\ Sudoeste da Bahia; analista ambiental pela \\ prefeitura municipal de Vitória da Conquista; e- \\ mail: lilamascarenhas@hotmail.com \\ Lorena Oliveira Matos Castro \\ Bacharel em Direito pela Faculdade \\ Independente do Nordeste; Advogada na \\ empresa Matos \& Matos advocacia; \\ Célia Maria Pedrosa \\ Doutora em Ciências Sociais pela Pontifícia \\ Universidade Católica de Minas Gerais; \\ professora do IFBAIANO, campus Valença; \\ celia.pedrosa@ifbaiano.edu.br
}

\section{RESUMO}

O licenciamento ambiental é um procedimento administrativo regulado pelas Resoluções 001/1986 e 237/1997, que constitui uma das principais maneiras de restringir e condicionar $\mathrm{o}$ uso dos recursos naturais. Este é um tema frequente na agenda de discussão das políticas públicas ambientais. Isto porque se enfrentam nessa questão interesses econômicos e de conservação do meio ambiente, aparentemente inconciliáveis. Neste estudo fazem-se algumas reflexões sobre esse procedimento administrativo no estado de Minas Gerais, observam-se as modificações nas normas que 0 regem, buscando verificar seus avanços e retrocessos. Trata-se de uma pesquisa explicativa, que pretende estabelecer conexão entre os desastres de barragens de rejeitos de minérios e as alterações normativas que tratam de aligeirar o procedimento de autorização das licenças no estado, além de abordar alguns princípios basilares do Direito concernente à questão. Considerou-se que as alterações que permitem a concessão de Licenciamento Ambiental Concomitante - LAC em nada garantirão o sistema de segurança dos grandes empreendimentos ou $\mathrm{O}$ amortecimento/mitigação/compensação dos impactos negativos, tanto para o meio ambiente quanto para a comunidade circunvizinha.

Palavras-chave: Barragens de rejeitos; Legislação; Licenciamento; Minério. 


\title{
Reflecting on the environmental licensing of mineral tailings dams in Minas Gerais (Brazil)
}

\section{Reflexiones sobre el licenciamiento ambiental de represas de desechos de minería en Minas Gerais (Brasil)}

\begin{abstract}
Environmental licensing is an administrative system regulated by Resolutions 001/1986 and 237/1997, constituting one of the main ways to restrict and condition the use of natural resources. It is a frequent point of discussion in the environmental public policies. This is due, persistent in the inseparable interest and economy of environment, seemingly irreconcilable. In this study are some reflections on the administrative procedure in the state of Minas Gerais, observing them as rules in them that are in line with the advances and setbacks. This is an explanatory research that searches make connections between disasters of ore tailings dams and as regulatory change, which aim at the accelerate the licensing procedure in the state of Minas Gerais, besides addressing some basic principles of Law concerning the issue. It was considered that the changes that allow the granting of Concurrent Environmental Licensing will not guarantee the safety of large enterprises or the damping / mitigation / compensation of negative impacts, both for the environment and the surrounding community.
\end{abstract}

Keywords: Tailings dams; Legislation; Licensing; Ore.

RESUMEN

El licenciamiento ambiental es un procedimiento administrativo regulado por las Resoluciones $001 / 1986$ y 237/1997, que constituye una de las principales formas de restringir y condicionar el uso de los recursos naturales. Este es un tema frecuente en la agenda de discusión de las políticas públicas ambientales. Eso porque se enfrentan en esa cuestión intereses económicos y de conservación del medio ambiente, aparentemente irreconciliables. En este estudio se hacen reflexiones sobre ese procedimiento administrativo en el estado de Minas Gerais, se observan las modificaciones realizadas en las normas que lo rigen, buscando verificar sus avances y retrocesos. Se trata de una investigación de tipo explicativo, que pretende establecer conexión entre los desastres en las represas de desechos minerales y las alteraciones normativas que buscan aligerar el proceso de licenciamiento en el estado, además de abordar algunos principios basilares del Derecho, concernientes a la cuestión. Se consideró que las alteraciones que otorgan la concesión de Licenciamiento Ambiental Concomitante - LAC, en nada garantizarán el sistema de seguridad de los grandes emprendimientos o la amortiguación/mitigación/compensación de los impactos negativos, tanto para el medio ambiente como para la comunidad aledaña.

Palabras-clave: Represas de desechos minerales; Legislación; Licenciamiento; Minerales.

\section{INTRODUÇÃO}

A construção do Direito Ambiental Brasileiro deu-se basicamente com o objetivo de regular o uso dos recursos naturais, em face à recente percepção de sua finitude, via redução de quantidade ou deterioração da qualidade (BORGES; REZENDE; PEREIRA, 2009). Outro objetivo não menos importante é a conservação dos recursos, de modo que eles mantenham o status de ecologicamente equilibrados, não somente para as atuais gerações como também para as futuras (PRIEUR, 2012). 
A legislação ambiental exige que se cumpram determinadas obrigações e deveres, restringindo e condicionando a utilização dos recursos naturais. O sentido último do Direito Ambiental, de acordo com Prieur (2012), é evitar a degradação ambiental e o esgotamento dos recursos naturais. Para este autor, a doutrina jurídica considera os direitos sobre o meio ambiente como um dos direitos e garantias fundamentais do ser humano, tanto no plano material como no plano formal, embora na Constituição da República, os mesmos estejam em títulos diferentes. Para Bertoldi (2000), se por um lado a atual Constituição é uma das mais ambientalistas do mundo, por outro, na prática jurídica observa-se uma infinidade de desafios para o reconhecimento do direito ambiental como direito humano, em decorrência de uma consciência eminentemente antropocêntrica e utilitarista.

Uma das principais maneiras pelas que a norma restringe e condiciona o uso dos recursos naturais é o licenciamento ambiental, instituído pela Lei 6938/1981 e regulado pelas Resoluções 001/1986 e 237/1997, ambas do Conselho Nacional do Meio Ambiente Conama. Estes instrumentos normativos exigem dos empreendimentos ou atividades poluidoras ou degradadoras do meio ambiente uma adequação para que suas atividades tenham seus impactos negativos reduzidos. Em face das competências legislativas complementares dos estados e municípios como entes da federação, o licenciamento ambiental pode adotar regras específicas, em função das peculiaridades locais, desde que seja observada a hierarquia legislativa.

Neste contexto, esse estudo teve como objetivo analisar as normas de licenciamento ambiental de Minas Gerais, especificamente quanto às barragens de rejeitos de mineração. Esse estudo se justifica tendo em vista os graves impactos dos recentes crimes ambientais no estado, em decorrência do rompimento das barragens de rejeitos de minérios de Mariana e Brumadinho e as recentes decisões dos legisladores mineiros.

\section{FUNDAMENTAÇÃO TEÓRICA}

A sociedade sempre alimentou a percepção de que aquilo que não pertence especificamente a alguém pode ser desfrutado por qualquer um. Seguindo essa linha de ideias, a concepção do termo caronista, se define como o indivíduo que recebe o 
benefício de um bem, porém, evita pagar por ele, esperando que outros custeiem o recurso disponível (PINDYCK; RUBINFELD, 2002 apud PASSUELO; OLIVEIRA; MENDES, 2014). Tal fato se observa, sobretudo, no processo natural de usufruto de um bem de uso comum do povo, ou seja, aqueles bens destinados à utilização geral pelos indivíduos e em iguais condições.

Hardin, em 1968, trouxe pela primeira vez a explanação sobre o fenômeno decorrente da utilização por todos de um recurso comum até que haja a sua exaustão completa. Para ele, um indivíduo buscará desfrutar de um recurso comum a todos para abstrair as possíveis vantagens individuais desse uso, potencializando seu ganho. Como decorrência, sendo esse recurso uma fonte finita, o desgaste adicional e gradativo do usufruto levará ao seu esgotamento.

Os recursos naturais são considerados como bens ambientais que integram, obviamente, o meio ambiente natural. A Constituição Federal da República de 1988, precedida pela Lei da Política Nacional do Meio Ambiente e por outras Constituições da América Latina, teve pela primeira vez no Brasil a inserção do tema meio ambiente no seu capítulo VI, artigo 225 (MACHADO, 2013).

Destaca-se aqui, a expressão 'bem de uso comum do povo', trazida pelo referido artigo: "Todos têm direito ao meio ambiente ecologicamente equilibrado, bem de uso comum do povo e essencial à sadia qualidade de vida, impondo-se ao Poder Público e à coletividade o dever de defendê-lo para as presentes e futuras gerações" (BRASIL, 2016, p. 131). Diversas são as posições doutrinárias acerca da categoria do bem ambiental. Para muitos defensores, ele se apresenta como uma classificação inédita.

De acordo com a maioria doutrinária, a Carta Magna possibilitou o surgimento de um novo entendimento sobre a natureza do bem para categorizar o bem ambiental: a tutela de bem jurídico de natureza difusa, que se caracteriza como sendo aquele cuja usufrutuária é a sociedade como um todo, portanto, os indivíduos não podem fazer uso dele sem afetar a coletividade e, por conseguinte, sem gerar conflitos sociais. Isso porque diferentes grupos na sociedade apresentam interesses contrapostos diante do mesmo bem; um exemplo é a preservação ambiental, que se opõe aos interesses econômicos industriais (SMANIO, 2000).

Levando-se em consideração o nível exponencial de degradação dos recursos naturais, alcançado sobretudo a partir da revolução industrial no século XVIII, faz-se 
necessária a intervenção do direito sob a tutela ambiental. Isso porque a relação entre homem e natureza tornou-se, por assim dizer, extremamente desequilibrada, alimentada pela industrialização e pelo consumismo. Os efeitos não afetaram a sobrevivência humana de modo imediato e perceptível, portanto, a preocupação com tais consequências veio posteriormente (MATTOS, 2008).

Apesar do discurso ecológico defendido por ambientalistas e aceito por muitos, o cenário da política ambiental na década de 1980, era visto tão-somente como limitação ao modelo de desenvolvimento do país por parte de segmentos e setores do governo e da iniciativa privada. Na década de 1990, porém, muitas mudanças começaram a ocorrer no país, possibilitando o empreendimento de algumas ações conduzidas por parte do governo central (SCARDUA; BURSZTYN, 2003). Um novo cenário começa a se delinear no campo da construção da normatização ambiental.

\section{METODOLOGIA}

O presente trabalho se define como uma pesquisa explicativa que busca fazer um paralelo entre os desastres de barragens de rejeitos minerais e as alterações normativas que buscavam aligeirar o procedimento de autorização das licenças. Analisaram-se leis e resoluções pertinentes ao licenciamento ambiental e deliberações normativas do Conselho Estadual de Política Ambiental de Minas Gerais, bem como com alguns princípios do Direito concernentes à questão.

\section{O PROCEDIMENTO DE LICENCIAMENTO AMBIENTAL MINEIRO}

O licenciamento é ponto de discussão frequente na pauta das políticas públicas ambientais. Isto porque persistem nessa questão interesses econômicos e de conservação do meio ambiente, aparentemente inconciliáveis. Ainda persevera para muitos o equivocado entendimento de que os condicionantes exigidos para o exercício do direito de empreender uma atividade, estabelecidos no procedimento do licenciamento, funcionam como entrave ao desenvolvimento do país. Contudo, não é justo que a sociedade arque com as consequências de passivos ambientais de empreendimentos privados, sem qualquer ônus para o empreendedor, enquanto ele 
continua obtendo o lucro a partir de sua atividade. Destaca-se também que muitas vezes as leis são modificadas por legisladores de plantão mediante interesses particulares. É neste contexto que se pretende analisar os maiores crimes ambientais por rompimento de barragem de rejeitos no Brasil, ocorridos em novembro de 2015 e janeiro de 2019 e suas relações com as modificações legislativas ocorridas no estado, relacionadas a este fato.

No estado de Minas Gerais os empreendimentos são enquadrados em classes de 1 a 6, levando-se em consideração o porte do empreendimento e seu potencial poluidor do ar, água e solo, conforme a Deliberação Normativa do Conselho Estadual de Política Ambiental - Copam $n^{\circ} 74 / 2004$ (COPAM, 2012). As atividades enquadradas nas classes 3 a 6, como é o caso das atividades de mineração, são consideradas potenciais causadoras de impactos ambientais significativos, logo estarão sujeitas ao rito de licenciamento que obedece às fases de Licença Prévia (LP), Licença de Instalação (LI) e Licença de Operação (LO).

Entre os casos de rompimentos de barragens de rejeitos de minérios destacam-se aqueles que tiveram maiores impactos no Brasil: os casos de Mariana e de Brumadinho em Minas Gerais. No primeiro, os derramamentos de rejeitos, que até hoje ocorrem em períodos de chuva desde o sítio da barragem até a foz do Rio Doce, destruíram praticamente toda a biodiversidade de um rio, causando impactos diretos e indiretos sem estimativa prevista de fim. Foram destruídas três comunidades inteiras (Bento Rodrigues, Paracatu e Gesteira) e 19 mortes foram registradas. Entre os impactos ambientais observou-se assoreamento de rio, liberação de lixívia em bacia, suspensão de fornecimento de água, mortandade de fauna aquática, famílias ribeirinhas desalojadas por inundação, entre outros (ZONTA; TROCATE, 2016). No que diz respeito ao julgamento e cumprimento das sanções penais em decorrência do crime cometido, verifica-se certa impunidade, visto que, quatro anos após a tragédia, pouco foi feito por parte das empresas responsabilizadas para recuperar a vasta área impactada.

Já o rompimento da barragem de rejeitos localizada em Brumadinho resultou na morte de 251 vítimas identificadas até o momento, enquanto outras 19 pessoas estão desaparecidas. Quase 12 milhões de metros cúbicos de lama percorreram 9 quilômetros destruindo pelo caminho as áreas operacional e administrativa da mina, casas, uma 
pousada, propriedades rurais, plantações, parte da floresta e um bairro do município de Brumadinho, desaguando no rio Paraopeba, um afluente do Rio São Francisco.

O que é pouco divulgado, ao contrário do que aconteceu com os desastres de Mariana e Brumadinho, é que os episódios com incidentes em barragens de rejeitos que causam perdas humanas, econômicas e ambientais, são relativamente comuns no estado de Minas Gerais (COSTA; FELIPPE; REIS, 2016). De 1986 até 2014, foram 15 as mortes confirmadas neste setor. Tais fatos denotam falhas graves no rito de licenciamento e fiscalização ambiental de empreendimentos minerários e barragens de rejeito (COSTA; FELIPPE; REIS, 2016).

A questão preocupante refere-se à aplicabilidade da legislação ambiental, a partir dos crimes de Mariana e Brumadinho, que são trazidos aqui justamente pelo alcance dos seus impactos de variadas ordens. Apesar das implicações desastrosas dessas tragédias, trazidas como exemplo ilustrativo da realidade jurídica ambiental, o Projeto de Lei 2.946 de 2015, cujo objetivo principal era flexibilizar o licenciamento ambiental e excluir o Ministério Público desse processo, foi aprovado pela Assembleia Legislativa do Estado de Minas Gerais, estranhamente 20 dias após o desastre de Mariana. Assim, no ano de 2016, com a edição da Lei 21.972/2016, o estado passou a ter novas regras de licenciamento ambiental para desburocratizar este procedimento administrativo e reduzir o passivo de autorizações do governo estadual. A posteriori, foi inserida nova norma, a Deliberação Normativa COPAM n² 217/2017, que revogou a Deliberação Normativa COPAM n 74/20014. Ela estabeleceu normas diferentes à classificação de acordo com o porte e potencial poluidor do empreendimento. O licenciamento no estado mineiro passou a ter diferentes modalidades, dependendo da classe do empreendimento e dos critérios locacionais de enquadramento, que pode ser trifásico, modalidade de licenciamento em que as licenças prévia, instalação e operação- são emitidas separadamente; ou em forma concomitante, no qual duas ou três licenças serão expedidas simultaneamente.

Ora, apesar de terem ocorrido inúmeros desastres com mineradoras no estado de Minas Gerais, o poder legislativo do estado entendeu ser necessário simplificar as regras de licenciamento. Assim, é cabível pensar aqui, em que sentido a legislação ambiental está caminhando atualmente e a que interesses estas modificações atendem. Uma questão fundamental pode ser suscitada dentro deste contexto: se os riscos com 
rompimentos de barragens de rejeitos continuam iminentes, os legisladores estariam realmente alcançando o alvo da problemática da mineração no estado de Minas Gerais?

Recordando os princípios basilares do direito ambiental, faz-se inevitável reportarse ao princípio da proibição do retrocesso ambiental. Tal princípio, em seu cerne, resguarda direitos proclamados que visam à manutenção do meio ambiente ecologicamente equilibrado, dos processos ecológicos essenciais, da qualidade, dignidade e da própria vida humana (BENJAMIN, 2011). Como bem colocado por Benjamin (2011, p. 61) “em nada se justificaria economizar aqui para gastar acolá, ou, pior, gastar muito mais adiante com medidas de recuperação do meio ambiente degradado, de mitigação e de adaptação".

Boa parte das barragens de rejeitos de mineradoras opta pelo método de construção à montante. Essa preferência se deve ao fato de ser o método mais econômico. Em contrapartida, essas barragens se apresentam mais instáveis, representando um ótimo exemplo do ponto mencionado por Benjamin. Respeitar o princípio da proibição de retrocesso, neste panorama, pouparia despesas, indenizações, capital natural e capital financeiro. Além disso, o retrocesso pode se dar no plano da existência (revogação de determinado instrumento), no plano da eficácia (debilitamento da força coativa da norma de desenho do instrumento) ou no plano da eficiência (com o aumento dos custos de transação na implementação, dificultando-se ou mesmo inviabilizando-se a fiscalização, por exemplo) (Benjamin, 2011, p.67-68).

O princípio da mutabilidade do Direito é cabível na maioria das regras jurídicas, visto que, de acordo com autores clássicos, o Direito deve submeter-se a uma regra de adaptação permanente, condizente com as necessidades evolutivas da sociedade em progresso. Entretanto, o meio ambiente, tal como os direitos humanos, não se encaixa nessa prerrogativa. Impede-se neste ponto, a tomada de decisão capaz de causar danos a eles. Assim sendo, reduzir ou revogar regras de proteção ambiental levaria à possibilidade de sua degradação, impondo danos às gerações futuras (PRIEUR, 2012).

Não obstante, na intenção de agilizar a análise e emissão de licenças, há de se indagar a real fonte da problemática ambiental em Minas Gerais como em qualquer outro estado do país. Piske (2016) ressalta vários fatores necessários para controlar a problemática da degradação ambiental e, entre eles, destaca o desenvolvimento de políticas públicas mais engajadas bem como uma efetiva fiscalização pelos órgãos de 
controle das atividades que degradam o ambiente, potencializada por uma melhoria das condições materiais, instrumentais e o aperfeiçoamento dos recursos humanos desses órgãos da administração (PISKE, 2016). Aligeirar o procedimento de autorização das licenças em nada garantirá o sistema de segurança dos grandes empreendimentos ou o amortecimento/mitigação/compensação dos impactos negativos, sobretudo os de mineração, tanto para o meio ambiente quanto para a comunidade circunvizinha.

\section{CONSIDERAÇÕES FINAIS}

Por fim, cabe ponderar brevemente sobre a valoração dos bens ambientais. De acordo com a economia ambiental, os recursos naturais podem ser qualificados como de valor econômico direto, que são aqueles relacionados aos bens obtidos pelas pessoas a partir da exploração dos recursos; e valor econômico indireto, atribuídos aos benefícios fornecidos pela biodiversidade ou mesmo ao potencial benefício futuro, para além do uso e exploração dos recursos (PRIMACK; RODRIGUES, 2001).

Trazer em pauta reflexões sobre pontos da evolução do Direito Ambiental no Brasil, inevitavelmente, leva à análise dos resultados de seu objetivo, ou seja, a conservação dos recursos naturais para gerações vindouras. Sendo assim, calha indagar: Quanto vale um rio inteiro? Cabe fazer também, uma avaliação ampla de seu significado. Trata-se não somente do valor do recurso hídrico por si mesmo, mas de populações aquáticas inteiras -desde peixes a invertebrados, anfíbios, répteis, plantas e ainda aves que dependiam das águas do rio-, bem como dos ribeirinhos que utilizavam o rio como meio de sobrevivência. Ecossistemas que, como tal, possuem uma história evolutiva que se perde no tempo. Para além do valor biológico, importa questionar o valor de centenas de vidas humanas, a qualidade de vida, a renda financeira e, por consequência, a dignidade dos habitantes das localidades atingidas. Quanto está sendo restituído por todos esses impactos diretos e indiretos?

Extrapolando os casos discutidos aqui, observa-se a aplicação da norma jurídica sendo negligenciada, esquecida, subestimada em diferentes esferas do Direito desde o âmbito local ao nacional. Que houve evoluções na legislação brasileira nas últimas décadas, não há como negar; porém, retrocessos que serviram a interesses particulares 
também se fizeram presentes neste enredo, contrários à lógica do Direito Ambiental como já defendido anteriormente.

\section{REFERÊNCIAS BIBLIOGRÁFICAS}

BENJAMIN, Antonio Herman. Princípio da proibição de retrocesso ambiental. In: ROLLEMBERG, Rodrigo et al. Princípio da proibição de retrocesso ambiental. Brasília: Senado Federal, 2011. Cap. 2. p. 55-72. Disponível em:

https://www.mpma.mp.br/arquivos/CAUMA/Proibicao\%20de\%2oRetrocesso.pdf> Acesso em: 20 out. 2017.

BERTOLDI, Marcia Rodrigues. O direito humano a um meio ambiente equilibrado. 2003. Disponível em: <https://jus.com.br/artigos/1685/o-direito-humano-a-um-meio-ambienteequilibrado>. Acesso em: 20 out. 2017.

BORGES, L. A. C.; REZENDE, J. L. P.; PEREIRA, J. A. A. Evolução da legislação ambiental no Brasil. Revista em Agronegócios e Meio Ambiente, 2 (3), 447-466, set./dez. 2009 - ISSN 1981-9951.

BRASIL. [Constituição (1988)]. Constituição da República Federativa do Brasil. Rio de Janeiro: Senado Federal, Coordenação de Edições Técnicas, 2016. 498 p.

CONAMA. Resolução $\mathrm{n}^{\circ} 237$ de 19 de dezembro de 1997. Disponível:

<http://www.mma.gov.br/port/conama/res/res97/res23797.html>. Acesso em: maio de 2018.

COPAM - Conselho Estadual de Política Ambiental (Minas Gerais). Deliberação $\mathrm{n}^{\circ}$ 177, de 22 de agosto de 2012. Estabelece critérios para classificação, segundo o porte e potencial poluidor, bem como os critérios locacionais a serem utilizados para definição das modalidades de licenciamento ambiental de empreendimentos e atividades utilizadores de recursos ambientais. Diário Oficial [do] Estado de Minas Gerais: caderno 1: Poder Executivo, Minas Gerais, ano 23, n. 217, p. 14, 06 dez. 2017.

COSTA, Alfredo; FELIPPE, Miguel; REIS, Gabriela. Licenciamento ambiental de grandes empreendimentos minerários: dos alarmes que ninguém escuta à tragédia no rio Doce. Revista Geografias, ano 1. n. 95, ago. 2016. Disponível em: https://www.researchgate.net/publication/306011267_Licenciamento_ambiental_de_gran des_empreendimentos_minerarios_dos_alarmes_que_ninguem_escuta_a_tragedia_no_r io_Doce. Acesso em: 10 set. 2017.

MACHADO, Paulo Affonso Leme. Direito ambiental brasileiro. 4 ed. São Paulo: Malheiros, 2013.

MATTOS, Eduardo da Silva. Desenvolvimento sustentável: uma análise histórica. Vitrine da Conjuntura, Curitiba, v. 1, n. 9, dez. 
2008. Disponível em: <https://img.fae.edu/galeria/getlmage/1/733582274161267.pdf>. Acesso em: 21 set. 2017.

MINAS GERAIS. Lei $n^{\circ}$ 21.972, de 21 de janeiro de 2016. Disponível em: <http://www.siam.mg.gov.br/sla/download.pdf?idNorma=40095> Acesso em maio de 2018.

PASSUELLO, Ana Carolina; OLIVEIRA, Celmar Corrêa de; MENDES, Carlos A. B.. Dilemas Ambientais em áreas urbanas: uma nova face da "tragédia dos comuns". 2014. Disponível em:

http://www.ciflorestas.com.br/conteudo.php?tit=dilemas_ambientais_em_areas_urbanas _uma_nova_face_da_tragedia_dos_comuns\&id=10738 >. Acesso em: 20 out. 2017.

PISKE, Oriana. Mariana: de quem é a responsabilidade pelo maior desastre ambiental brasileiro?. 2016. Disponível em: <https://www.tjdft.jus.br/institucional/imprensa/artigosdiscursos-e-entrevistas/artigos/2016-1/mariana-de-quem-e-a-responsabilidade-pelo-maiordesastre-ambiental-brasileiro-juiza-oriana-piske>. Acesso em: 18 nov. 2017.

PRIEUR, Michel. O Princípio da Proibição de Retrocesso Ambiental. In: BRASIL. Senado Federal (Org.). O PRINCíPIO DA PROIBIÇÃO DE RETROCESSO AMBIENTAL: Comissão de Meio Ambiente, Defesa do Consumidor e Fiscalização e Controle. Brasília: Senado Federal, 2011. Cap. 1. p. 11-54. Disponível em: <http://www2.senado.leg.br/bdsf/handle/id/242559>. Acesso em: 8 nov. 2017.

PRIMACK, R.B.; RODRIGUES, E. Biologia da Conservação, Editora Planta, Londrina, 2001, 327p.

SCARDUA, Fernando Paiva; BURSZTYN, Maria Augusta Almeida. Descentralização da política ambiental no Brasil. Sociedade e Estado, [s.l.], v. 18, n. 1-2, p.291-314, dez. 2003. FapUNIFESP (SciELO). http://dx.doi.org/10.1590/s0102-69922003000100014.

SMANIO, Gianpaolo Poggio. Tutela Penal dos Interesses Difusos. São Paulo: Atlas, 2000.

ZONTA, Marcio; TROCATE, Charles (org.). Antes fosse mais leve a carga: reflexões sobre o desastre da Samarco/Vale/BHP Billiton. Marambá, PA: Editorial iGuana, 2016. E-book (233 p.). Disponível em: http://www.ufjf.br/poemas/files/2016/11/Livro-Completo-com-capa.pdf. Acesso em: 21 ago. 2017. 